\title{
Peningkatan Kesadaran terhadap Cagar Budaya di Kotabaru Melalui Kegiatan Jelajah Wisata Heritage bagi Generasi Muda di Kota Yogyakarta
}

\author{
Fahmi Prihantoro \\ Departemen Arkeologi, Fakultas Ilmu Budaya, Universitas Gadjah Mada \\ Posel: fahmi_p@ugm.ac.id
}

\begin{abstract}
Kotabaru is one of the cultural heritage areas in the city of Yogyakarta which has a high degree of vulnerability to destruction because it is in the central business district. On the other hand, one of the conservation efforts depends on the level of public awareness to preserve it. The younger generation has the potential to support the preservation of cultural heritage. One of the ways is by increasing the awareness of the young generation towards cultural heritage. This activity aims to increase the cultural heritage awareness of the Yogyakarta younger generation in the Kotabaru Cultural Heritage Area. The method is done by means of heritage adventure. The results of this activity show that the level of knowledge and awareness of participants increasing after participating in the activity. They know the history, the characteristic of the building and the conservation efforts. Awareness of cultural heritage is obtained when visiting the Museum Sandi as a form of implementation of preservation and utilization of cultural heritage properly.
\end{abstract}

Keywords: heritage awareness, young generation, heritage adventure, Kotabaru Heritage

\begin{abstract}
Abstrak
Kotabaru merupakan salah satu kawasan cagar budaya (KCB) di Kota Yogyakarta yang memiliki tingkat kerentanan yang tinggi terhadap perusakan karena berada di kawasan pusat bisnis. Di sisi lain, upaya pelestarian, salah satunya, tergantung pada tingkat kesadaran masyarakat untuk melestarikannya. Generasi muda merupakan kelompok yang berpotensi besar dapat mendukung upaya pelestarian cagar budaya. Salah satunya yaitu dengan meningkatkan kesadaran generasi muda terhadap cagar budaya. Kegiatan ini bertujuan untuk meningkatkan kesadaran generasi muda di Kota Yogyakarta terhadap cagar budaya di Kawasan Cagar Budaya Kotabaru. Metode yang dilakukan adalah dengan kegiatan jelajah wisata heritage. Hasil dari kegiatan ini menunjukkan bahwa tingkat pengetahuan dan kesadaran peserta meningkat setelah mengikuti kegiatan tersebut. Mereka mengetahui sejarah, bentuk bangunan, dan upaya pelestarian yang dilakukan. Pemahaman kesadaran tentang cagar budaya diperoleh ketika mengunjungi Museum Sandi sebagai bentuk implementasi pelestarian dan pemanfaatan cagar budaya dengan baik.
\end{abstract}

Kata Kunci: kesadaran cagar budaya, generasi muda, jelajah wisata heritage, Kawasan Cagar Budaya Kotabaru 


\section{Pendahuluan}

Yogyakarta saat ini dikenal sebagai kota pendidikan, kebudayaan, pariwisata, dan juga sejarah. Sebutan yang terakhir layak disematkan kepada Kota Yogyakarta karena kota ini telah menjadi saksi perjalanan sejarah, mulai Kasultanan Mataram, Kasultanan Yogyakarta, Yogyakarta pada masa kolonial, hingga Yogyakarta pada masa revolusi ketika sempat menjadi ibu kota Republik Indonesia. Beberapa hal lain untuk memperkuat sebutan Yogyakarta sebagai kota sejarah yakni Yogyakarta memiliki banyak peninggalan material, seperti bangunan berarsitektur kolonial dan kawasan-kawasan bersejarah di beberapa sudut kota, antara lain, kawasan Keraton Kasultanan Yogyakarta yang menjadi pusat pemerintahan Kasultanan Yogyakarta, kawasan nol kilometer yang menjadi pusat pemerintahan kolonial Belanda dengan rumah residen dan benteng Vredeburg-nya, serta beberapa kawasan lain, seperti kawasan kolonial di Kotabaru dan Bintaran serta kawasan Pecinan dan Kauman.

Sejarah pengembangan kota kolonial di Yogyakarta dimulai sejak perjanjian Giyanti 1755 yang membagi Mataram menjadi dua: Kasultanan Yogyakarta dan Kasunanan Surakarta. Seiring pembangunan pusat Kasultanan Yogyakarta dibangun pula Lodji Besar sebagai rumah tinggal militer VOC, yang kemudian menjadi Benteng Vredeburg dan juga Lodji Kebon sebagai rumah tinggal Residen Yogyakarta. Bertambahnya orangorang Eropa di Yogyakarta menyebabkan Lodji Besar tidak lagi representatif untuk ditinggali. Oleh karena itu, meluaslah kawasan huni orang-orang Eropa, khususnya warga sipil, ke wilayah di sebelah timurnya yang kemudian disebut Lodji Kecil (Knapp, 1999:75). Tahun 1905 menjadi momentum penting pengembangan morfologi kota-kota kolonial di Jawa (Handinoto, 1998:8). Di Yogyakarta, kawasan kolonial berkembang ke sebelah utara yang kemudian disebut Kotabaru. Kawasan ini tumbuh dengan corak arsitektur Indis, yang menggabungkan arsitektur Eropa dan lokal serta jalan-jalan yang lebar dan melengkung (Soekiman, 2011:110). Fasilitas-fasilitas publik seperti sekolah, rumah sakit, dan gereja juga muncul seiring pertumbuhan kota kolonial baru tersebut. Pada perkembangannya, kawasan kolonial juga meluas di Bintaran, yang ditandai dengan keberadaan gereja Santo Yosef dan rumah orang-orang Eropa lainnya. Kini, di kawasan-kawasan tersebut, sebagian besar bangunan masih cukup utuh dan masih dapat dinikmati.

Berdasarkan Pasal 1 Angka 6 Undang-Undang RI No. 11 Tahun 2010 Tentang Cagar Budaya, yang berbunyi "Kawasan cagar budaya adalah satuan ruang geografis yang memiliki dua situs cagar budaya atau lebihyang letaknya berdekatan dan/atau memperlihatkan ciri tata ruang yang khas", diperlukan kebijakan dan strategi pelestarian kawasan tersebut sebagai upaya pengendalian pemanfaatan ruang dalam konteks kekinian. Implementasi upaya itu adalah dengan membentuk kawasan cagar budaya di berbagai tempat di Daerah Istimewa Yogyakarta. Pertama, berdasarkan Surat Keputusan Gubernur No. 186/2011 ada enam Kawasan Cagar Budaya yang telah ditetapkan, yaitu Kotagede, Keraton, Malioboro, Pakualaman, Kotabaru, dan Imogiri. Kedua, Kawasan Prambanan dengan potensi tinggalan masa klasik (Hindu-Buddha) sebagai Kawasan Cagar Budaya Peringkat Nasional. Hal itu berdasarkan Keputusan Menteri Pendidikan 
dan Kebudayaan RI No.278/M/2014 Tentang Satuan Ruang Geografis Prambanan. Mengingat sebagai kawasan dengan peringkat nasional, batasan wilayahnya mencakup dua wilayah provinsi, yaitu D.I.Y. dan Jawa Tengah.

Pada saat ini, kawasan Kotabaru sangat rentan terhadap perusakan bangunan yang ada di kawasan cagar budaya. Kawasan ini secara ekonomi berada di wilayah yang strategis sehingga dinamika perubahannya sangat tinggi. Kasus pembongkaran terhadap bangunan rumah di kawasan cagar budaya Kotabaru terjadi dewasa ini. Media massa banyak menyoroti dan menyayangkan pembongkaran bangunan tersebut. Hal ini membuktikan bahwa diperlukan langkah-langkah konkret untuk menyelesaikan masalah ini sehingga pembongkaran terhadap bangunan-bangunan di kawasan cagar budaya kota baru tidak terus terjadi.

Salah satu upaya yang dapat dilakukan adalah meningkatkan kesadaran terhadap generasi muda dalam rangka ikut melestarikan cagar budaya. Generasi muda perlu mengetahui nilai-nilai penting bangunan cagar budaya agar dapat menyikapi dengan baik berbagai cagar budaya yang ada di kawasan Kotabaru. Generasi muda adalah masa depan bangsa. Dengan demikian, upaya peningkatan kesadaran terhadap cagar budaya bagi generasi muda adalah wujud masa depan keberlanjutan cagar budaya. Salah satu bentuk kegiatan yang dapat dilakukan yaitu dengan menyesuaikan karakter generasi muda saat ini. Model jelajah wisata dapat menjadi kegiatan yang menarik minat para generasi muda untuk mengikuti kegiatan ini.

\section{Rumusan Masalah}

Terkait dengan latar belakang masalah di atas, salah satu kawasan cagar budaya di Kota Yogyakarta, yaitu Kawasan Cagar Budaya (KCB) Kotabaru, tidak dapat dilepaskan dari persoalan tersebut. Kawasan ini menghadapi tingkat ancaman yang cukup tinggi terhadap perusakan cagar budaya karena potensi keberadaan bangunan-bangunan cagar budaya yang tinggi sekaligus letaknya yang berada di kawasan pusat ekonomi.

Berkaitan dengan hal tersebut, muncul masalah mengenai cara meningkatkan kesadaran masyarakat, terutama para generasi muda, untuk memiliki kesadaran dan pemahaman terhadap pelestarian cagar budaya. Berkaitan dengan generasi muda diperlukan cara yang lebih menarik dan kreatif untuk dapat diterima oleh mereka. Oleh karena itu, tulisan ini fokus pada upaya untuk meningkatkan kesadaran terhadap cagar budaya di Kotabaru melalui jelajah wisata heritage bagi generasi muda di Kota Yogyakarta.

\section{Tujuan}

Kegiatan ini bertujuan untuk mengupayakan peningkatan kesadaran terhadap cagar budaya bagi generasi muda di Kota Yogyakarta melalui bentuk kegiatan yang menarik, yakni berupa jelajah wisata di KCB Kotabaru, Yogyakarta. Para peserta dikenalkan dengan berbagai cagar budaya dari berbagai aspek, seperti arkeologi, antropologi, sejarah, 
dan pariwisata sehingga mereka dapat mengenal lebih jauh berbagai peninggalan warisan budaya masa lalu.

Tujuan lainnya adalah agar generasi muda memiliki kepedulian terhadap pelestarian Cagar Budaya bagi masa depan kebudayaan di Kota Yogyakarta. Kegiatan ini juga dapat mewujudkan kepedulian pihak perguruan tinggi (dosen dan mahasiswa) untuk ikut andil dalam proses pengabdian kepada masyarakat sesuai dengan bidang ilmunya.

\section{Manfaat}

Manfaat yang diharapkan dari kegiatan ini adalah dapat memberikan alternatif cara baru untuk meningkatkan kesadaran masyarakat, terutama generasi muda di kota Yogyakarta agar memiliki kesadaran dan pemahaman terhadap cagar budaya. Model kegiatan melalui jelajah wisata lebih sesuai dengan minat generasi muda saat ini karena mereka dapat mengapresiasi secara langsung sekaligus berwisata.

\section{Metode Pelaksanaan Kegiatan}

Kegiatan ini berupa jelajah wisata dengan berjalan kaki mengunjungi berbagai situs bangunan yang ada di kawasan cagar budaya Kotabaru. Peserta diajak melihat berbagai bangunan cagar budaya dan dijelaskan sejarah serta dinamika bangunan yang ada di Kotabaru. Peserta mengunjungi Museum Sandi di Kotabaru sekaligus mengenal wisata museum. Peserta juga diajak berdiskusi mengenai berbagai persoalan yang berkaitan dengan upaya pelestarian dan pengelolaan bangunan cagar budaya dan kawasan cagar budaya.

Lokasi jelajah wisata mengambil sebagian KCB Kotabaru, khususnya di sisi barat dan selatan, mengingat luasnya area serta waktu yang terbatas. Kegiatan ini dilaksanakan pada Sabtu, 12 Mei 2018 mulai pukul 08.00-12.00 WIB.

\section{Analisis Data}

Data dianalisis menggunakan pendekatan data kualitatif berupa hasil diskusi dan aktivitas jelajah wisata. Untuk mengetahui hasilnya dilakukan diskusi prakegiatan, kegiatan jelajah wisata, dan diskusi akhir kegiatan. Dari ketiga fase tersebut dapat dilihat seberapa jauh pemahaman awal peserta dan setelah mengikuti kegiatan tersebut. Peningkatan pengetahuan kesadaran dari peserta diharapkan akan meningkat setelah mengikuti kegiatan jelajah wisata heritage tersebut. Hal tersebut dapat diketahui dari diskusi akhir kegiatan.

\section{Hasil dan Pembahasan}

\section{Diskusi Prakegiatan}

Diskusi prakegiatan dilakukan sebelum kegiatan jelajah wisata heritage dilakukan. Hal 
ini bertujuan untuk mengetahui seberapa jauh peserta memiliki pengetahuan dan pemahaman terhadap cagar budaya dan upaya pelestariannya. Dari hasil diskusi tersebut, sebagian besar peserta belum pemah melakukan kegiatan serupa, khususnya yang berkaitan dengan pengetahuan tentang cagar budaya. Mereka belum mengetahui cukup banyak tentang potensi cagar budaya di Kotabaru dan upaya pelestariannya. Pemahaman

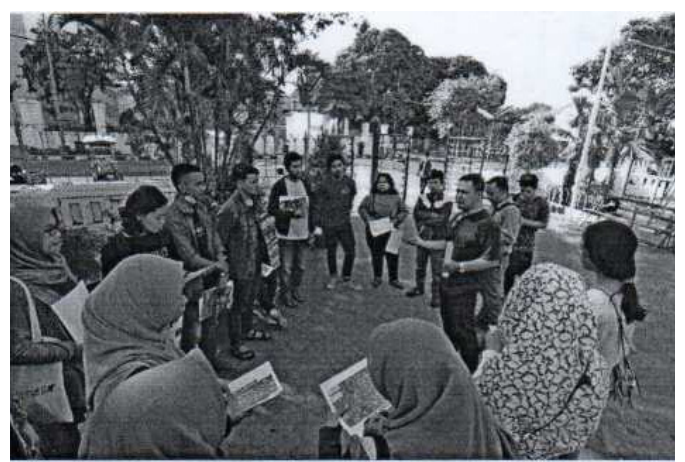

Ilustrasi 1. Peserta Mendapatkan Informasi tentang Kegiatan. (Sumber: Dok. Pribadi) sebagian besar peserta tentang Kotabaru adalah kawasan yang terdiri atas sebagaian bangunan kuno dan menjadi pusat kawasan bisnis, terutama bisnis kuliner, seperti Kafe SiLol, Raminten, Mirota, dan kuliner kaki lima saat malam hari. Mereka tidak mengetahui sejarah perjuangan pertempuran Kotabaru yang terjadi pada 1949. Mereka juga tidak mengetahui informasi tentang sejarah kawasan Kotabaru sebagai permukiman Belanda pada saat itu. Mereka juga belum mengetahui cukup banyak tentang kebijakan pemerintah terhadap pelestarian kawasan Kotabaru sebagai Kawasan Cagar Budaya (KCB) yang harus dilindungi dari berbagai ancaman perusakan. Dari diskusi ini dapat disimpulkan bahwa pemahaman peserta terhadap Kotabaru masih terbatas pada substansi yang tampak, terutama bangunan yang dimanfaatkan untuk bisnis kuliner, sedangkan sejarah dan pengetahuan terhadap cagar budaya masih sangat sedikit.

\section{Kegiatan Jelajab Wisata}

Pelaksanaan kegiatan Jelajah Wisata Heritage diawali dengan pemberian informasi tentang kawasan Kotabaru, yakni tentang sejarah berbagai bangunan di dalamnya dan kebijakan pemerintah untuk menetapkan Kotabaru sebagai kawasan cagar budaya (KCB). Kegiatan dilanjutkan dengan menyusuri rute yang telah ditetapkan untuk mengenal berbagai peninggalan berupa bangunan rumahrumah tinggal, perkantoran, tempat ibadah, dan juga sekolah yang ada di

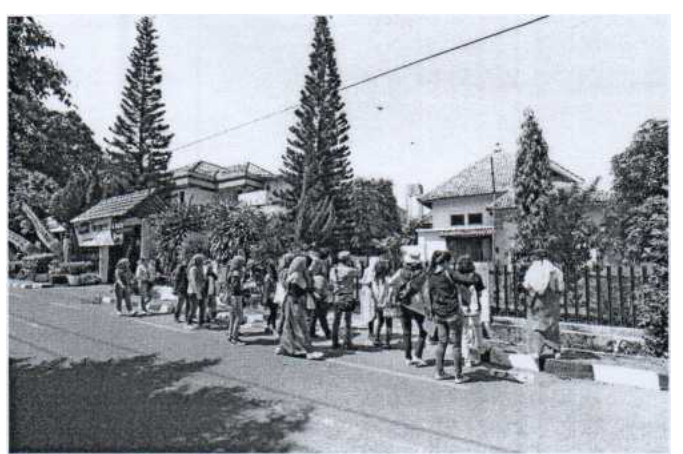

Ilustrasi 2. Peserta Melihat Langsung Bangunan Heritage di Kotabaru.

(Sumber: Dok. Pribadi) kawasan cagar budaya Kotabaru. Peserta dijelaskan tentang sejarah, bentuk arsitektur, serta upaya perlindungan dan pemanfaatan berbagai heritage tersebut. Pada kegiatan ini, peserta mengapresiasi secara langsung karena mereka mendapatkan informasi tentang bangunan-bangunan cagar budaya di Kawasan Kotabaru seperti Masjid Syuhada, beberapa rumah tinggal, Gereja Kotabaru, SMA 3, dan SMP 5, termasuk juga melihat 
lansekap tata ruang kawasan Kotabaru secara langsung. Mereka mengenal istilah bangunan Indis, konsep garden city pada Kotabaru, dan boulevard. Sebagian besar peserta sangat menikmati kegiatan ini karena baru pertama kali mengikuti kegiatan seperti ini sekaligus mendapatkan informasi tentang heritage di Kotabaru.

Selanjutnya, peserta juga mengunjungi Museum Sandi di Kotabaru yang merupakan contoh upaya perlindungan dan pemanfaatan heritage, khususnya untuk museum dan pariwisata. Peserta diberikan pemahaman bahwa bangunan heritage dapat dilindungi dengan cara memanfaatkan bangunan tersebut untuk kegiatan masa kini berupa museum dan pariwisata. Bangunan heritage tidak harus diganti dengan bangunan baru untuk fungsi baru, bahkan bangunan Museum Sandi dapat dimanfaatkan pula untuk aktivitas swafoto dengan latar belakang bangunan lama yang dipelihara dengan baik. Peserta menunjukkan antusias yang cukup tinggi ketika mengunjungi Museum Sandi. Museum ini sangat layak untuk wisata museum karena memiliki pelayanan yang baik dari berbagai segi, seperti penyambutan tamu yang baik dan menarik. Peserta diberikan suvenir yang berkaitan dengan permainan sandi. Museum ini juga memilki pemandu yang profesional dan menarik, yang melayani semua tamu atau pengunjung museum. Fasilitas museum juga sangat bagus, yakni dengan kebersihan dan fasilitas AC yang baik sehingga nyaman bagi para pengunjung.

Dengan demikian, hasil dari kegiatan ini adalah peserta mendapatkan informasi yang cukup banyak tentang cagar budaya dari berbagai aspek seperti sejarah, arsitektur bangunan dan kota, serta pengelolaan kawasan cagar budaya dan wisata di Koatabaru. Informasi ini akan menjadi memori yang kuat bagi peserta karena dilakukan dengan cara yang menarik dan terlibat langsung.

\section{Diskusi Akhir Kegiatan}

Diskusi akhir kegiatan dialakukan setelah jelajah wisata heritage. Diskusi ini dilakukan untuk mendapatkan informasi seberapa jauh peningkatan pemahaman peserta setelah mengikuti jelajah wisata heritage. Dari hasil diskusi dapat diketahui bahwa peserta memiliki tingkat pengetahuan, pemahaman, dan kesadaran yang meningkat dari sebelum

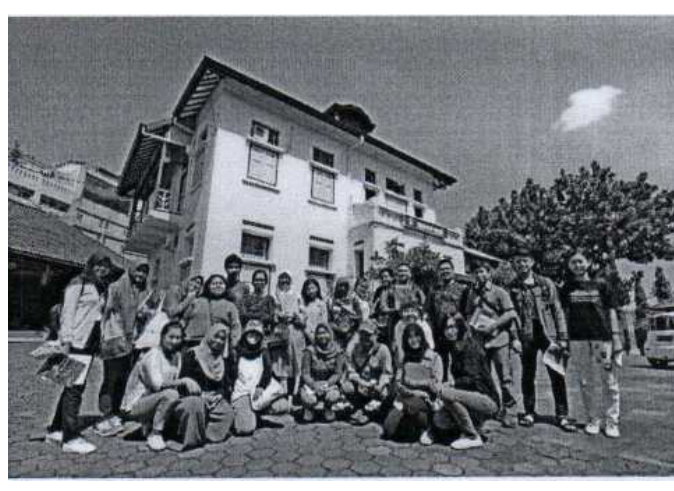

Ilustrasi 3. Peserta Berfoto Bersama di depan Museum Sandi. (Sumber: Dok. Pribadi)

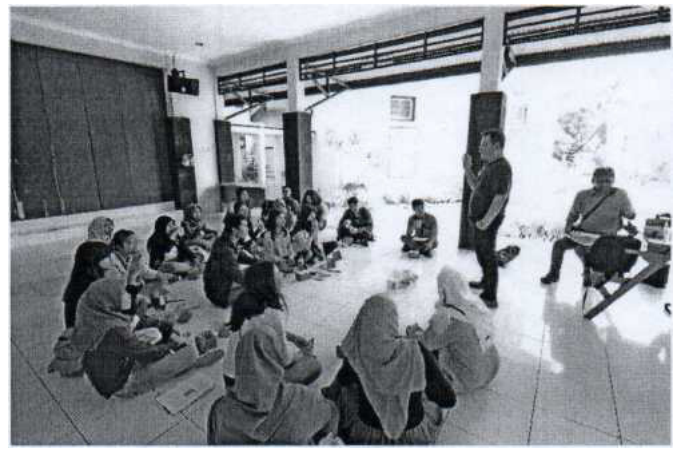

Ilustrasi 4. Peserta Melakukan Diskusi Akhir Kegiatan. (Sumber: Dok. Pribadi) 
mengikuti kegiatan tersebut. Peserta mengungkapkan bahwa kegiatan ini menarik dan memberikan informasi yang sangat penting, khususnya yang berkaitan dengan kawasan cagar budaya. Meskipun waktunya sangat singkat, mereka mampu menangkap informasi dengan baik. Beberapa kendala yang diungkapkan adalah cuaca yang cukup panas dan harus berjalan kaki sehingga cukup mengganggu kenyamanan.

\section{Kesimpulan}

Kegiatan ini memberikan kesimpulan bahwa jelajah wisata heritage di Kotabaru mampu meningkatkan pengetahuan, pemahaman, dan kesadaran peserta terhadap cagar budaya. Pengemasan kegiatan melalui perpaduan belajar dan wisata terbukti dapat diterima dengan baik dan efektif. Model kegiatan seperti ini diharapkan dapat dikembangkan di tempat lain guna meningkatkan kesadaran masyarakat terhadap cagar budaya.

\section{Daftar Pustaka}

Handinoto. (1998) "Perubahan Besar Morfologi Ko ta-ko ta di Jawa pada Awal dan Akhir Abad XX" dalam Jurnal Dimensi Arsitektur, Vol. 26, Desember 1998.

Knaap, Gerrit. (1999). Cephas, Yogyakarta: Photography in the Service of the Sultan. Leiden: KITLV.

Soekiman, Djoko. (2001). Kebudayaan Indis: Dari Zaman Kompeni sampai Revolusi. Jakarta: Komunitas Bambu.

Surat Keputusan Gubernur No. 186/2011 Tentang Kawasan Cagar Budaya di D.I.Y. Undang-Undang Republik Indonesia No. 10 Tahun 2011 Tentang Cagar Budaya. 